\title{
El Apostolado de la Prensa. La actuación del salesiano Bernardo Gentilini
}

\author{
Manuel Loyola Tapia $\left(^{*}\right)$
}

\begin{abstract}
RESUMEN
Durante el primer tercio del siglo XX, la Iglesia católica chilena impulsó el proyecto evangélico editorial de la Buena Prensa. Entre las diversas acciones e iniciativas que esto implicó, las emprendidas por el presbítero salesiano Bernardo Gentilini, constituyeron unas de las más destacadas. A base de fuentes primarias, damos a conocer aquí un semblante general de su actuación como editor y propagandista eminente de la Buena Prensa, tópico inaugural de la moderna edición de masas en Chile.
\end{abstract}

\section{Palabras clave:}

Buena Prensa - prensa impía - Congregación Salesiana - Iglesia católica chilena apostolado de la prensa.

(*) Doctor en Estudios Americanos, mención Historia, Instituto de Estudios Avanzados de la Universidad de Santiago de Chile. Académico de la Escuela de Periodismo de la misma Universidad.

Artículo enviado el 8 de agosto de 2011. Aceptado por el Comité Editorial el 14 de mayo de 2012.

Correo electrónico: manuel.loyola@gmail.com 


\begin{abstract}
During the first third of the twentieh century, the Chilean Catholic Church promoted the evangelical proyect of the Godd Press. Among the various actions and iniciatives that this involved, those undertaken buy presbyter Bernardo Gentilini constituted one of the most prominent. Based on primary sources, we present here a general countenance of his performance as propagandist of the Good Press, one of the inaugural moments of the mass media in Chile
\end{abstract}

Keywords:

Chilean catholic church - Salesians - good press - apostolate of the press - unholy press.

\title{
Presentación
}

La historia del libro y la edición en Chile no dispone aún de trabajos que den cuenta de manera completa y circunstanciada de las distintas alternativas y acciones que conformaron el campo editorial chileno en los años en que éste comienza a adquirir presencia y articulación pública, esto es, a comienzos del siglo XX. Señalamos esto a pesar de algunos avances que se han venido verificando durante la última década, particularmente los provenientes desde el ámbito de los estudios literarios. No obstante, dejaremos para otra ocasión ahondar sobre este tema a fin de no apartarnos del propósito del momento.

Existe, por cierto, interrogantes generales que balizan nuestra tarea, así como inquietudes más puntuales que contribuyen a la caracterización historiográfica que nos mantiene ocupados desde hace un tiempo: ¿La configuración de la moderna cultura urbana en Chile contempló la concurrencia de la cultura impresa? De ser efectiva tal concurrencia, ¿cuáles fueron sus contornos específicos en materia de producción, tópicos editoriales, distribución y lectura? ¿Quiénes fueron sus principales actores y gestores? ¿De qué manera entidades tan relevantes de la vida social chilena, como la Iglesia católica, se dispusieron frente al fenómeno de la palabra impresa?

Tomando en consideración una experiencia específica del desarrollo editorial de inicios del siglo XX -el proyecto de la Buena Prensa Católica y la actuación del salesiano Bernardo Gentilini- buscamos aquí revelar no sólo algunas de las señas del despliegue editorial católico de entonces, sino también, arrojar algo de luz sobre el contexto de época en que el fenómeno editorial chileno comenzó a tomar cuerpo.

\section{Bernardo Gentilini, una pasión impresa}

Como parte del arribo de la Congregación Salesiana a Chile, acaecida en las últimas décadas del siglo XIX, una acción decisiva en su asentamiento fue la organización de estructuras formadoras de religiosos y sacerdotes que permitieran la consolidación 
del proyecto pastoral inspirado en las enseñanzas y carisma de su fundador, San Juan Bosco ${ }^{1}$. En este contexto, en 1895, llega al país Bernardo Gentilini (Boloña, 1875). Con 20 años de edad inicia sus estudios de teología en el primer seminario salesiano de Santiago, obteniendo su presbiterado en 1899. Culminado este proceso, comienza una encomiable labor editorial y propagandística que intensificará a lo largo de su vida, al punto de tener que dejar la Congregación, pasando al clero secular en 1932, como manera de atender a los múltiples trabajos que le demandaba convertir la iniciativa personal del Apostolado de la Prensa, en un nuevo instituto religioso. Y fue, precisamente, en medio de estos trajines que le sorprendió la muerte en Santiago, en septiembre de 1936.

Poseedor de una vasta erudición clásica y doctrinaria, descolló también por dominar diversos idiomas que contribuirían a sus finalidades editoriales: al italiano y castellano, agregó un óptimo conocimiento del francés e inglés, lenguas que tuvo ocasión de conocer y practicar en varios viajes y largas estadías en Estados Unidos y Europa.

No es fácil poder señalar algunas características de nuestro personaje. Las escasas referencias a su persona expuestas en la bibliografía religiosa chilena, no avanzan más allá de lo anotado al comienzo e, incluso, los datos sobre las fechas de su nacimiento y muerte, no son del todo concordantes. Nuestra perplejidad se incrementa aún más al revelársenos, por vía de la investigación, la intensidad y extensión de su desempeño como autor y compilador de cientos de folletos de polémica y proselitismo religioso, actividad que complementó con una no menos vigorosa labor como editor, productor y distribuidor de miles de opúsculos de difusión doctrinaria.

Pero si bien de su vida y sus avatares cotidianos no tenemos tanto más que decir, en subsidio de ello, referencias de contexto sí nos ayudan a explicarnos al personaje y su obra, aspectos que, a fin de cuentas, son los que aquí me importa indicar. Para ello, nos valdremos de una apreciación de conjunto deducida de los únicos testimonios que nos legara: el extenso catálogo de sus iniciativas editoriales.

De los antecedentes reunidos, podemos sugerir que su derrotero editorial estuvo jalonado por experiencias que, de modo cada vez más complejo y ascendente, lo llevaron a involucrarse en mayores desafíos y pretensiones. Lo sorprendente a este respecto, es que este derrotero se nos muestra como una evolución "natural", esto es, como la manifestación de una especie de proyecto $a b$ ovo que su autor habría tenido definido desde muy temprano ${ }^{2}$.

La primera mención editorial de nuestro personaje corresponde a la publicación de los quincenarios La Spiga y la Spiga D’Oro, entre 1900 y 1904, a los que se habría unido, en igual año, otro título, la Giornata D'Amore, del que no hemos podido hallar ningún ejemplar.

\footnotetext{
${ }^{1}$ Simón Kuzmanich B., Presencia Salesiana, 100 Años en Chile. La Expansión: 1888-1920, Editorial Salesiana, Santiago, 1990. ${ }^{2}$ No disponemos de datos de la experiencia y formación intelectual de Gentilini antes de su llegada a Chile. Sólo nos cabe conjeturar que su eventual conocimiento previo de la prensa católica italiana, le habría permitido disponer de una noción proyectual que aplicaría luego en nuestro país.
} 
Publicados en italiano en la Tipográfica de la Spiga (con sede en el Colegio Salesiano Sagrada Familia de Macul, Santiago), las ediciones de los primeros mencionados alcanzaban a las 16 páginas en formato pequeño $(9 \times 11 \mathrm{~cm})$. Sus hojas contienen muchos de los aspectos que conformó el acervo literario de nuestro autor-editor hasta los días de su muerte, a saber, el sentido trascendente de la existencia, las Verdades cristianas, la aceptación de los designios de Dios, la entrega a una vida de obediencia y abnegación, la abstinencia del cuerpo, el repudio a los "falsas religiones" y sus voceros, la presencia del mal en los tiempos modernos, etc.

Nutrido de innumerables citas bíblicas y de los Padres de la Iglesia, sus glosas son, de común, comentarios o apostillas a los problemas del bien, la felicidad, el trabajo, la lectura, la sana recreación, la presencia cotidiana de María o de Jesús, o la enseñanza de los santos. Su finalidad es llamar la atención del lector sobre las verdades reveladas y la adaptación de la vida a la simplicidad y alegrías ahí contenidas. De este modo, no estamos frente a la pluma de un teólogo que pretendiera difundir su verbo desde la complejidad de la filosofía tomista con todo su aparato dialéctico o sintáctico, sino frente a un publicista que, confiado plenamente en las armas de la fe que ha abrazado, buscó repartirla más allá de los templos y capillas apelando a una modalidad discursiva axiomática y directa, articulada en torno enunciados básicos y generales, a los que le seguían comentarios y argumentaciones, a favor o en contra, muy propia de la tarea de catequesis.

Consideramos que haber comenzado su tarea editorial utilizando el italiano y el francés (la primera, como lengua propia, y la segunda, seguramente adquirida en sus años de niñez y juventud) importó, de una parte, hacer sus primeras artes autorales en idiomas mayormente conocidos por él, soslayando, para su apasionada labor, dificultades con un idioma -el español- que, al parecer, no logró asumir a la perfección, al menos desde el ángulo de la grafía ${ }^{3}$. De otra parte, estas ediciones en lenguas latinas favorecieron la pretensión personal de hacer de su trabajo un producto que estuviese conectado con áreas del mundo que eran la cuna y la avanzada de la cultura cristiana. Basta revisar sus relatos de viajes, especialmente a Europa, para darse cuenta de la admiración que tenía por el pasado y las realizaciones del arte, la literatura o el pensamiento desarrollados en esas tierras. Refuerza esta imagen, la escasa atención que pone en el acontecer y culturas de nuestra región, llegando incluso a expresar palabras de desprecio por lo que observa en Río de Janeiro, Montevideo o Buenos Aires, réplicas de mal gusto y de segunda mano de la magnificencia parisina o romana.

Una señal que corrobora el europeísmo editorial de Gentilini, es el hecho de que estas primeras producciones se ofrecieron en venta por su editor en moneda francesa (francos), y no en pesos chilenos. Sin importarnos que efectivamente dispusiera de compradores europeos, mencionemos que el gesto en sí implicaba el supuesto de que sus trabajos podían contar con dos formas de adquisición: por la vía de la distribución directa a Europa a través de una trama de contactos eclesiales, o por

\footnotetext{
${ }^{3}$ En los pocos manuscritos que se conservan de Gentilini, podemos percatarnos de las fallas de su escritura, particularmente en el terreno de los tiempos verbales, artículos o pronombres. Al tenor de esto, suponemos que la mayor parte de su despliegue propagandístico y editorial, realizado en idioma español, hubo de contar con la colaboración revisora de diversas personas cuyos nombres, casi en su totalidad, no fueron señalados en las ediciones.
} 
venta, también directa, en el país, a un público selecto pero con lazos externos, fueran estos permanentes $\mathrm{u}$ ocasionales. Como tendremos ocasión de ver, este interés de Gentilini por dar y darse a conocer en ámbitos lectorales católicos bastante más versados, pudientes y extensos que el de Chile, fue una constante que lo acompañó recurrentemente en su vida.

A partir de 1901, La Spiga y La Spiga D'Amore tendrán una versión en idioma español por medio de un "periodiquito quincenal" titulado Espigas de Amor. Manteniendo el formato pequeño de 9x11 cm -muy a la usanza de las ediciones devocionales-, contaba de 8 páginas, impresas a un color. Su vigencia, al igual que la edición italiana, se mantendrá hasta 1904. Su propósito era llevar "a las almas las inspiraciones de Jesús (...) para la santificación y la felicidad de la vida". En cuanto a su título, Gentilini señala haber escogido la expresión Espigas, por constituir "la más bella y rica expresión de la vida y del amor, su maduración que nutre e inicia eternos caminos de vida, es el modo de manifestación del amor Divino en la tierra"

Una indicación relevante al final de cada entrega, era la frase "Consérvese todos los números para formar después un libro", señal de que, lejos de ver satisfecha su labor con 8 o 16 páginas cada quince días, tenía previsto ampliar y hacer perdurar la difusión de sus notas por medio de formatos con más presencia simbólica. Es así como en 1903, con igual pie de imprenta, da a conocer por espacio de 2 meses, un folletín de 4 páginas adjunto a la edición regular de La Espiga, donde ahonda en mensajes de moralidad religiosa. Más elocuente aún, fue la aparición en este mismo año de lo que podríamos calificar como el primer libro de su autoría: Chistes y Verdades. En 128 páginas, esta obra reunió un conjunto de fábulas, anécdotas, cuentos, máximas y viñetas -en buena medida provenientes de las publicadas en la folletería periódicarotuladas como "lecturas de sana entretención".

En estos años de inicio, Gentilini no sólo se aboca a la escritura y edición de textos que podríamos llamar lato sensu periódicos. De igual modo se ocupa de la producción de formatos gratuitos de difusión masiva que debían ser repartidos en todas las acciones educacionales y sociales de la Congregación, amén de las parroquias y lugares de oración.

En efecto, en 1902, inicia la impresión de Hojita de propaganda, folletos de 8 páginas de $10 \times 16 \mathrm{~cm}$, impresos a un color (negro) en papel barato o de baja calidad. El contenido de la Hojita fue definido por él como "remedios de gotas amargas para muchas de las enfermedades del alma", a saber, la tendencia social al pecado, la lujuria, el ateísmo o la ambición. Lugar preponderante en sus mensajes tenía la "lucha contra el indiferentismo religioso", realidades de su tiempo que identificaba tanto en el ateísmo como en la difusión de las ideas masónicas y del protestantismo. "No cabe ser indiferente en este mundo", manifestaba (...) El indiferentismo religioso delante de Dios es un delito".

Luego de 4 años en tareas educacionales y editoriales en Sagrada Familia de Macul, en 1905 la Congregación lo destina a hacerse cargo del Colegio Técnico de Concepción,

\footnotetext{
${ }^{4}$ Espigas de Amor, $\mathrm{N}^{\circ} 1,10$ de agosto de 1901, p.1.
} 
ciudad donde, por más de un lustro, continuará como de editor de La Espiga (ahora en singular, y quitándole el complemento "de Amor"). Modifica su periodicidad quincenal a mensual, incrementando también sus páginas a 50 . El formato, más ampliado, lo asemeja claramente a la edición de un libro corriente $(11 \times 13 \mathrm{~cm})$. La dirección del Colegio de Concepción le permitió tomar en sus manos la imprenta del lugar, a la que en adelante le da el nombre de Tipografía de la Espiga, tal como ocurriera en Macul.

Fue en este lugar donde avisa de la publicación, en francés e italiano, de sus trabajos santiaguinos, conformado una primera colección o biblioteca: se trataba recopilaciones fundidas en varios volúmenes de 160 a 180 páginas, titulados librairie des Epis Glanés ${ }^{5}$, de la Spiga d'Oro ${ }^{6}$ y de la Giornata d'amore ${ }^{7}$, títulos publicados en Santiago por el Colegio Sagrada Familia. La oferta pública de los mismos reitera los precios en francos con su equivalente en pesos nacionales.

En julio de 1908 aparece en La Espiga la publicidad de un nuevo libro de Gentilini: El diario del alma, compilación de apuntes comenzados en 1904 que ahora reúne en 6 tópicos, abordando temas sobre las verdades eternas, la paciencia y la mortificación, la castidad y la vida religiosa, la devoción. A finales de este mismo año, La Espiga publicita las bendiciones de que ella y sus lectores habían sido objeto por parte del Papa Pío X, a raíz del primero de los viajes que Gentilini hiciera a Europa en $1908^{8}$. Al reconocimiento papal le seguía otro, del Obispo de la Diócesis. Datos diversos de este viaje serán expuestos por el presbítero en otra publicación suya del año siguiente, Hojas de un diario de Viaje, donde expone con detalle el cúmulo de impresiones que le granjeó su salida temporal del país, a partir del propio cruce de Los Andes hacia Buenos Aires, su estadía en el barco que lo trasladó a España, y su periplo por Francia, Alemania e Italia, lugar donde tuvo acceso a una breve entrevista con el Papa.

En el segundo semestre de 1908, y por espacio de casi 5 años, retoma la línea de las impresiones masivas iniciada en 1902, dando a conocer una Hoja Volante, "publicación semanal destinada al pueblo". Encabeza los ejemplares con la frase de León XIII "La prensa católica es la gran necesidad de los tiempos modernos". Cada número estaba compuesto de 4 páginas en tamaño estándar de 21,5x31 cm y su contenido estuvo dedicado principalmente a "combatir las sectas protestantes". De circulación gratuita, su financiamiento dependió de la venta de cantidades por la vía de la suscripción, las erogaciones voluntarias de los creyentes y el uso de parte de los ingresos provenientes de los óbolos por rogativas y gracias a María Auxiliadora.

\footnotetext{
${ }^{5}$ En su anuncio publicitario se puede leer: "Petit periodique intime qui a pour but de porter aux ames les inspirations de Jésus. Anecdotes, pensées et petit conseils".

6 "Periodichino intimo che ha per iscopo di portare alle anime de inspirazioni de Gesú, i palpiti del suo Cuore Eucaristico, y suo consigli per la santificaciones e per la felicitá della vita".

7 "Libriccino intimo che dovre besere la mana giornaliera di tutti coloro che tendono alla perfezione religiosa".

${ }^{8}$ Bernardo Gentilini, Diario de Viaje, Apostolado de la Prensa, Santiago, 1924, cuarta edición. En Europa recorrió Barcelona, Lourdes, Paris, Reims, Amberes, Londres y Roma. De su encuentro con Pío X, hizo el siguiente relato: “Cuando se acercaba a mí, tuve la ocasión de clavar en él una mirada investigadora y descubrir en sus ojos una inefable dulzura (...) y estampaba en su mano mi ardiente beso: -¿De Concepción, de Chile?- repitió, mirándome con interés (...) en esa mirada leí un rasgo de predilección por Chile (...) Santísimo Padre -le dije en italiano- pídole una bendición especialísima para mí, para mis parientes y amigos, y para los cooperadores de la Obra salesiana de Concepción", p.161.
} 
Un aspecto culminante en su desempeño editorial de este período, estuvo en la creación, en mayo de 1909, de la Sociedad de Buenas Lecturas de Concepción, con asiento en el colegio Salesiano que dirigía. Es a partir de entonces que sus empeños los alude a "la obra de salvación del Apostolado de la Prensa". En lo sucesivo, tanto las producciones ya emprendidas como las venideras que aparecieran en la Diócesis, debían orientarse bajo la línea de gestión de la dicha Asociación, convocándose a los católicos de la zona a hacerse parte de sus esfuerzos haciéndose socios colaboradores de manera parcial o perpetua, calidades que variaban según los aportes en dinero a que se comprometieran de forma regular. También se tenía en mente acudir a un modelo comercial más formal mediante la generación de una sociedad por acciones. El valor de cada título sería de 50 pesos, y los interesados podían tomar más de una9

No contamos con evidencia que fundamenten que el modelo organizacional accionario recién dicho haya sido presentado a la Sociedad de Buenas Lecturas por el sacerdote Gentilini. Es probable que sí, y ello no porque se tratara de una novedad, sino porque, más allá de la suerte que corriera la empresa, la propuesta sintonizaba con el ánimo de entusiasmo que lo embargaba luego de su estadía en Europa y la entrega de la venia papal a su quehacer. Un indicador de este influjo fue la apertura en su colegio penquista de un "Buzón de las Buenas Lecturas", inspirado en puntos similares que había observado en España y Francia. El Buzón correspondía a un lugar de acopio donde los fieles debían llevar tanto las "buenas" como las "malas" lecturas: las primeras, para ser redistribuidas, y las segundas, para su censura y eliminación.

Por medio de la Hoja Volante, de marzo de 1911, nos enteramos de un nuevo viaje de Gentilini "...en atención a una importante comisión de sus superiores". El destino en la oportunidad fue Estados Unidos, en particular, a Nueva York, donde permanecería hasta finales de aquel año ${ }^{10}$. Con esto, concluye la edición de La Espiga.

Su alejamiento de Chile no implicó la suspensión de sus trabajos editoriales ligados a Concepción, pues, sea porque habría dejado diversos trabajos listos para prensa, o porque los habría ido enviando desde Nueva York, lo concreto es que en marzo del citado año 11, se inicia la publicación de una nueva serie de folletos mensuales bajo el rótulo de El Apóstol de la Prensa, "Órgano especial de la Sociedad de la Prensa y Centros Católicos". En su totalidad estos folletos son de autoría de Gentilini ${ }^{11}$.

En la secuencia de acciones editoriales que describimos, la colección de El Apóstol de la Prensa pero, por sobre todo, los resultados de su viaje a EE.UU. representaron para nuestro personaje una suerte de rito de paso, esto es, el tránsito final en la maduración de ideas y hechos que le impusieron la necesidad de dar un salto más definitorio. Nos referimos a la próxima instalación en nuestro país una organización exclusivamente

\footnotetext{
${ }^{9}$ Desconocemos si esta propuesta prosperó, aunque lo más probable es que ella no haya resultado en virtud del permanente desfinanciamiento que afectó a la mayor parte de los proyectos católicos de la Buena Prensa.

${ }^{10} \mathrm{Al}$ parecer, su estadía se prolongó por dos o tres años, oportunidad en que al parecer realizó salidas a Europa. Así deducimos de algunos acápites de su texto sobre el párroco norteamericano, donde alude al conocimiento personal de los libros católicos ingleses, en Londres. Bernardo Gentilini, El Clergyman norteamericano, Apostolado de la Prensa, Santiago, 1915, p. 35.

${ }^{11}$ Con una cantidad de páginas variable (de 32 a 64), y en tamaño de libro $(12,5 \times 18 \mathrm{~cm})$, la serie de El Apóstol se mantendrá con aceptable regularidad hasta mediados de 1917, totalizando la suma de 64 opúsculos (ver listado de títulos al final de estas páginas).
} 
dedicada al desarrollo editorial católico: El Apostolado de la Prensa (AP).

La manifestación de que ya se estaba en el umbral de una organización que, rebasando los particularismos practicados hasta entonces, debía surcar, en lo venidero, por espacios más prometedores y expectantes, lo llevó, a su retorno a Chile, a someter a prueba lo alcanzado durante una década de trabajo: la experiencia, los contactos, los respaldos, las bendiciones jerárquicas, el respeto y admiración de terceros, la demostración de obediencia, fidelidad y abnegación dentro y fuera de la Congregación, además de las muestras palpables de todo lo escrito y publicado ${ }^{12}$.

Las escasas informaciones que tenemos a mano, nos mueven a señalar que su regreso al país, habría sido directamente a Santiago, entablando relaciones con los medios de elite del catolicismo capitalino, tanto del clero como del laicado. Entre 1915 y 1916, ofrece numerosas conferencias públicas entre los círculos de la Universidad Católica, de colegios católicos de clase alta, así como en la influyente Liga de Damas Chilenas. Esta dinámica le permitió no sólo hacerse más conocido, ganando en prestigio dado su enorme bagaje literario y vivencial, sino, a la vez, obtener los apoyos morales y materiales que exigía la consolidación de su proyecto del AP.

Hacia comienzos de 1917, el titular del obispado capitalino emite la autorización y da las pautas para la constitución del AP como instancia diocesana. Algunos meses más tarde, en noviembre de ese mismo año, Bernardo Gentilini es nombrado Director diocesano de la obra en representación del Metropolitano ${ }^{13}$, seguido de un Presidente (Martín Lira Smith) y un Secretario (Manuel Hidalgo H.).

Antes de revisar el acontecer editorial expedido por el Apostolado de la Prensa, conviene que cerremos lo dicho sobre la primera década de la actuación de Gentilini, aludiendo a un par de cuestiones siempre vitales a los proyectos de esta naturaleza: su financiamiento y difusión.

La publicística católica de comienzos del siglo XX (aunque no sólo ella, obviamente), no desconocía que sus lectores y receptores no era ni podía ser un público demasiado extenso. Al analfabetismo de una porción considerable de la población (entre el $40 \mathrm{y}$ el 50\%, en 1907), se unía la disparidad relativa en el consumo de productos impresos, o el desinterés (también relativo) por consultar este tipo específico de mensajes (religiosos). No obstante, y pesar de todo ello, la generación y oferta de estos formatos experimentó en la época una abundancia desconocida hasta entonces.

Es cierto que las prácticas de la fe católica (y cristianas, en general), tenían en el impreso un recurso de sustentación bastante extendido desde mucho antes, sólo que, hasta fines del XIX, su empleo se remitía a materiales expresamente elaborados para estos fines, como eran la infinidad de láminas pías de santos, vírgenes o del lacerado corazón de Jesús, o de otras tantas hojitas con las intenciones del mes, con las normas del calendario litúrgico, de fiestas de guardar, ayunos, rezos o abstinencias.

\footnotetext{
${ }^{12}$ Entre los saludos y buenos augurios de la curia internacional que Gentilini menciona a modo de respaldo a su tarea, están las diversas notas que recibiera de obispos norteamericanos y sudamericanos.

${ }^{13}$ A la sazón, era Obispo de la Arquidiócesis de Santiago don Juan Ignacio González Eyzaguirre.
} 
Es decir, hasta entonces, el impreso era un medio estrictamente funcional a prácticas devocionarias, no teniendo, desde un punto de vista masivo, otras formas de aplicación o uso.

La asunción en Chile de la Buena Prensa hubo de romper, precisamente, este reduccionismo del impreso tradicional, proporcionando alternativas diversificadas de emisión y lectura, si bien todas habrían de regirse por las orientaciones de la dogmática tradicionalista en boga. ¿Cómo sostener y fructificar en el empeño, más cuándo se buscaba ensanchar el círculo de los destinatarios para beneficio de su propia salvación? ¿Cómo proporcionar "buenas lecturas" a sectores que, a pesar de que supieran leer, no estaban habituados a adquirir diarios, libros o revistas? La respuesta no podía ser otra que la gratuidad como eje de la circulación de impresos entre los más, y la cooperación, entre los menos, para hacer viable el esfuerzo.

En general, el conjunto de publicaciones de la Buena Prensa eclesial -y las lideradas por Gentilini no fueron una excepción- dispusieron de precios, sea para sus ejemplares "sueltos" (individuales) o por cantidades. Estos precios resultaron ser siempre más bajos -del orden del $50 \%$ o más- que los previstos para otras ediciones civiles o no religiosas contemporáneas ${ }^{14}$. Que así fuera, se debió a que en sus costos primaba por sobre todo el mecanismo de la transferencia o subsidio derivado de diversos aportes que nada tenían que ver con la venta real. Me refiero a la obtención de donativos en efectivo o en especies materiales de valor, la realización de bazares, veladas y rifas, pago de mandas y gracias, compromisos de limosnas, recolección de dinero en misas. Ciertamente, el hecho de que la mayor parte de los oficios y gestiones que demanda la producción y circulación de impresos fuesen ejecutadas como trabajos inherentes a las funciones sacerdotales cotidianas, también reportaba ahorros considerables, a lo que se agregaban los servicios gratuitos de muchos creyentes y cercanos a la Iglesia.

En estos términos, la distribución cursaba eminentemente por la gratuidad de los productos a los potenciales destinatarios -el pueblo devoto y trabajador-, reservándose lo propiamente comercial de los mismos -a valores muy bajos, como ya hemos observado- a acuerdos de suscripción por parte de las personas e instancias que sí tenían las posibilidades para ello, revistiéndose tal procedimiento de las debidas señales públicas de reconocimiento de estos compromisos para con la fe, los pastores y sus obras de salvación. De hecho, fue frecuente que en las páginas de estos impresos se dieran las gracias a quienes tomaban o renovaban "las acciones" suscriptoras, ofreciéndoseles homenajes y misas, en especial cuando fallecían.

La suscripción, además de su temporalidad semestral, anual o a perpetuidad, se practicaba por cantidades de ejemplares ${ }^{15}$ y no por números únicos, en la medida que estaba implícita su entrega (gratis) a grupos relativamente estables de personas,

\footnotetext{
${ }^{14}$ En 1910, un kilo de harina flor o un kilo de carbón espino -dos productos de alto consumo popular entonces- costaban 25 centavos. Los sueltos de cualquier boletín o folleto de cuño católico, tenían valores nominales que no sobrepasaba los 10 centavos.

${ }^{15}$ Se exceptuaron del mecanismo de la suscripción por volumen -aunque no de la temporalidad- las publicaciones de índole periódicas, como eran las revistas o libros. Las ediciones de estos podían ir de mensuales a trimestrales. En lo que toca a las ediciones de difusión masivas (hojas de propaganda, boletines, folletos), cuya periodicidad era por lo común semanal o quincenal, las cantidades iban de 10 hasta los 1.000 ejemplares.
} 
como eran las que se ubicaban en cárceles, fundos, parroquias, colegios, dispensarios, círculos obreros, obras sociales de San Vicente de Paul y hospitales.

Una práctica relevante de este mecanismo fue el uso de las estampillas de correos como medios de pago. La concentración de la labor impresora en pocas ciudades (desde luego, Santiago, seguida de Concepción y Valparaíso), la carencia de servicios de flete y traslado de carga, los distintos lugares de residencia de los suscriptores o la destinación de los ejemplares a sitios que no eran el domicilio del contratante, llevaron a los centros editores a sugerir que los pagos se hicieran por medio del envío, junto a la hoja de suscripción, del equivalente en sellos. Desde luego, se descartaba por inseguro el despacho de dinero en efectivo. Por su parte, los giros y letras, siendo utilizados, imponían trámites que era preferible evitar. En cambio, las estampillas agilizaban totalmente la operación, sin necesidad de tener que disponer de recursos frescos para los despachos postales ${ }^{16}$.

Esta modalidad de financiamiento y de distribución de base corporativa, se mantendría en paralelo al desarrollo mercantil de la edición en Chile, incluyendo la católica. Su desaparición irá en consonancia -amén de otras variables modernizadoras- con la aparición de un campo editorial más profesionalizado, hacia los años 30 del siglo XX. Pero tampoco en esto podríamos decir que el cambio sorprendió sin respuesta al área editorial eclesiástica. Al contrario, ya en el propio Gentilini, y en otros religiosos que simultáneamente con él animaban la multiplicación de iniciativas editoriales a comienzos del XX, encontramos el empeño por abrir y publicitar puntos de venta a la calle, cuyo efecto inmediato permitía fortalecer la vocería institucional en el terreno público, sin dejar de lado el ganancial que el gesto reportaba a la propia arista editora.

¿De qué modo se gestó esta disposición? pues aprovechando lo existente. En parroquias, templos, imprentas, colegios, locales de reunión de la asociatividad católica, oficinas y lugares de trabajo de laicos militantes, se comienza a dar paso a la conformación de expendios o librerías y, un poco más tarde, de bibliotecas, con lectura fija o circulante (es decir, sin o con préstamos a domicilio).

La indicación de los lugares de consulta y venta, obligaba a la caracterización, aunque fuese mínima, con detalles básicos e imprescindibles a la oferta: ubicación física, casillas de correo, precios, títulos, tipo de encuadernación, descuentos, personas a cargo. Más tarde, a medida que los contactos entre productores se ampliaba y los productos se expandían, encontraremos en los anuncios nuevos artículos "del negocio": escapularios, estampas sagradas ("en papel de calidad"), figuras de yeso y bronce, rosarios, entronizaciones, novenarios, recuerdos de primera comunión, confirmación o matrimonio, "letrillas" de diversión, lecturas infantiles, saetillas... No faltando, en el caso de los sitios más consolidados, el ofrecimiento de suscripciones a revistas y libros extranjeros, prevenientes de Buenos Aires, Madrid, Barcelona o París.

\footnotetext{
${ }^{16}$ Todo nos hace suponer que el valor de las suscripciones consideraba a la vez el costo de los envíos. Como parte del cometido ordinario, es probable que las encomiendas de suscripciones religiosas hayan estado subsumidas en las condiciones favorables (no necesariamente de gratuidad) que disponían las entidades católicas en sus relaciones con sus contrapartes públicas. Esto, al menos hasta 1925, año en que oficialmente se sanciona la separación Iglesia/Estado.
} 


\section{El Apostolado de la Prensa: 1911-1936}

El Reglamento del Apostolado" ${ }^{17}$ le indicaba como objeto "la preservación y propagación de la fe por medio de la buena prensa". Para ello, debía volcar sus empeños en la difusión de los buenos libros, de diarios, periódicos y hojas instructivas, con especial atención entre las personas que estuvieran fuera del alcance sacerdotal. A la base de este "programa", concurría la convicción de que "en estos tiempos", las buenas lecturas eran el medio más efectivo para la defensa y propagación de la fe "en las naciones civilizadas". Además de lo expuesto, el AP debía contribuir al sostenimiento de toda la prensa católica, en especial de los "sanos periódicos locales". Operativamente, el proyecto aprobado debía estructurarse en torno a un núcleo -una Casa de la Buena Prensa- desde el cual se gestaran y mantuvieran una red de centros locales en parroquias, iglesias, colegios y demás obras católicas. El lema de la obra era el de "Instaurar todas las cosas en Cristo".

$\mathrm{Su}$ financiamiento debía correr por cuenta de las acciones propias. Desde luego, la venta de publicaciones y suscripciones, pero también la recepción de limosnas y donativos, además de "todos otros medios" que contribuyeran al fondo social. En tanto obra social, el AP promovería la admisión a su seno de todo católico de cualquier condición, edad o sexo, quienes, a cambio, recibirían diversos tipos de compensaciones materiales y espirituales, goces, estos últimos, que dejaba abierta la posibilidad para que hubiesen asociados difuntos, los que, por vía del sufragio (obra buena que se aplica por las almas del purgatorio), serían igualmente beneficiados ${ }^{18}$.

Los centros locales -siguiendo el modelo de la obra de "Propagación de la Fe"19se conformarían a partir de un grupo de celadores y celadoras, quienes, a su vez, tenían que captar adherentes (socios), creándose Coros de al menos diez personas. El conjunto de centros de una Diócesis dependerían de un Consejo Central o Superior, nivel compuesto por un comité de Caballeros (coadyuvado por otro de Señoras) y presidido por un Director diocesano nombrado por el Obispo de la diócesis. A su vez, en la calidad de instancia ejecutiva (Directorio), el Director diocesano se acompañaría de un equipo de 3 a 4 asesores salidos del Consejo de Caballeros. Estos asesores tomarían responsabilidades de Presidente, Secretario, Tesorero u otras, durando tres años en sus funciones, pudiendo ser reelegidos. Su desempeño debía ser ad-honorem. Finalmente, consignemos que una vez al año el Directorio debía convocar a asamblea plenaria de socios y colaboradores, rindiendo cuenta de la marcha y movimiento

\footnotetext{
17 "Reglamento General de la Asociación Apostolado de la Prensa", en Bernardo Gentilini, El Libro del Apóstol de la Prensa, Santiago, Apostolado de la Prensa, 1918, pp. 147 - 152.

${ }^{18}$ Las categorías de socios estaban señaladas de la siguiente manera: Miembro cooperador contribuyente, 1 peso al año; Miembro Anual, 3 pesos al año; Miembro por 10 años, 10 pesos; Miembro Fundador, 1.000 pesos de una vez, o 100 pesos anuales por 10 años; Benemérito Bienhechor, cualquiera que aportara a la obra por medio de legados o limosnas de alguna consideración.

${ }^{19}$ Obra Misional Pontificia reconocida como tal por Pío XI en 1922. Su origen se remonta a la actuación de María Paulina Jaricot (Lyon, Francia, 1820). Entre sus objetivos, se destacan: Informar, sensibilizar y educar el espíritu misionero, suscitando el interés por la evangelización universal en todos los sectores del pueblo de Dios: las familias, las parroquias, los jóvenes, los movimientos apostólicos, las asociaciones, las comunidades, las escuelas, los enfermos y ancianos; $\mathrm{y}$, promover la ayuda recíproca entre las diferentes iglesias locales, tanto en el campo espiritual como material y el intercambio de personal apostólico entre las mismas.
} 
anual del Apostolado ${ }^{20}$.

En sus 25 años de vigencia ${ }^{21}$, el Apostolado de la Prensa (AP) publicó 234 títulos de obras socio-religiosas. De extensión mediana, ocasionalmente excedieron las 150 páginas en formato vertical de tamaño $12,5 \times 18 \mathrm{~cm}$. Impresos a un color en portada e interior, todos estos opúsculos se debieron a la pluma de Bernardo Gentilini, principal artífice e impulsor de esta empresa ${ }^{22}$.

Del total de títulos indicados, un 30\% correspondieron a reediciones o reimpresiones de trabajos que el Padre Gentilini compuso entre 1900 y 1917, y que había dado a conocer tanto en Santiago como en Concepción, según hemos descrito previamente. Según las Memorias de los últimos años del AP, el editor salesiano cuantificaba en casi un millón el número de copias o ejemplares impresos de este fondo, desde aproximadamente 1905 en adelante, cifra que no deja de ser impresionante para la época, y aún para nuestros días ${ }^{23}$.

Organizada la producción en 19 bibliotecas o colecciones ${ }^{24}$, la cobertura de relaciones comerciales del AP -de acuerdo a lo que expone en sus Boletines Bibliográficos- se expandió más allá de nuestras fronteras, alcanzando a países como Filipinas (Oceanía), El Salvador, Panamá, México, Ecuador, Perú, Argentina y Uruguay, en nuestra región, y España, en el hemisferio norte. No tenemos registros que nos hablen de la frecuencia, destinos, montos y cantidades de publicaciones que el AP habría enviado a esos puntos, de suerte que nos es imposible acercarnos a una exacta apreciación acerca del impacto que estos "mercados" habrían suscitado en la gestión regular de la obra. Lo que sí hemos podido constatar es la presencia de una decena de títulos del AP en antiguas bibliotecas, bases de datos y comercio de libros "raros y antiguos", puestos en portales web de Argentina y España. Obviamente, los vínculos epistolares y viajes de Gentilini al extranjero, permiten dar un nivel de veracidad a las noticias del Boletín Bibliográfico ${ }^{25}$.

\footnotetext{
${ }^{20}$ Las cuentas y balances anuales debían constar por escrito en Memorias periódicas. No hemos encontrado copia de alguna de ellas. Reproducción de diferentes párrafos de las mismas se hallan en lo que fue la publicación oficial de la entidad, el "Boletín del Apostolado de la Prensa", publicación de aparición irregular que comenzó en mayo de 1924 y se extendió hasta mediados de 1935.

${ }^{21}$ Desconocemos la fecha exacta de creación del Apostolado por parte de Gentilini. Lo más probable es que nunca haya tenido un acto claro de fundación como organización. Los alcances que él hace sobre sus orígenes, más parece una construcción ex post, al mencionar, hacia el final de su vida, que la obra habría tenido su comienzo en 1905. De nuestra parte, consideramos que la iniciativa tuvo su partida más articulada en 1911, con el comienzo de la serie El Apóstol de la Prensa. En este sentido, la obra habría perdurado por espacio de 25 años, acabando con la desaparición física de su mentor, en 1936.

${ }^{22}$ Por lo corriente, la autoría obedece a su nombre real. Sin embargo, en cerca del 15\% de los libros, suscribe utilizando seudónimos tales como Glaneur D’Epis, Le Glaneur, o Gabriel de la Paz. Particularmente, este último "nombre" lo empleó en libelos de propaganda antisocialista y antisoviética.

${ }^{23}$ No sabemos, a ciencia cierta, si el dato de un millón de impresiones es correcto o no. Si rebajáramos el número a la mitad, a pesar de no contar con elementos que avalen este ejercicio, la proporción de 500.000 ejemplares sigue siendo considerable. $\mathrm{Al}$ dividirla por los 234 títulos, resulta un promedio general de más de 2.000 copias por título. A su vez, al prorratear las 234 obras en 25 años, da un estimado medio de casi 10 títulos por año. Ambos cálculos, siendo absolutamente relevantes para inicios del siglo XX, son todavía importantes para las condiciones actuales de nuestra actividad editorial.

${ }^{24}$ Ver detalle al final.

${ }^{25}$ En su edición de junio de 1924, Gentilini indica haber llevado recientemente al correo "una carretada" de publicaciones del AP. Eran 1.200 ejemplares de títulos varios dirigidos a Riobamba, Guayaquil, Panamá y Buenos Aires; "Boletín del Apostolado de Prensa", Santiago, Año I, 2, 1924, p. 4.
} 
Otra referencia que abona a favor de la internacionalización del AP, es el ofrecimiento en venta de una cincuentena de títulos de publicaciones de edición foránea que la obra ofrece a sus suscriptores y público en general, los cuales podían ser consultados y comprados en las librerías de la organización: la instalada en la Casa Inspectorial Salesiana ${ }^{26}$, y la abierta en la propia sede que el AP tendrá a partir de fines de 1926, ubicada en Chile-España con Irarrázaval, Nuñoa ${ }^{27}$. De acuerdo a la prácticas habituales del negocio librero, es probable que estas "importaciones" se hayan cubierto con canjes de ediciones del AP enviadas a editores y librerías del exterior, todas ellas de propiedad o relacionadas con estructuras eclesiásticas de sus respectivos lugares.

En el plano de esta modalidad de pagos por libros enviados o recibidos, cabe de igual modo presumir que las transacciones pudieron haber considerado la entrega de derechos de autor a las casas editoriales de fuera del país. Así al menos podría desprenderse de la presencia en Chile de textos de Gentilini publicados en España (Bruno del Amo), Suiza (Benziger \& Co), Herder (Alemania) o Argentina (Colegio Pío IX y Editorial Difusión).

El Apostolado ocupó, una vez llegado Gentilini de los EE.UU. (1914), dependencias de la Casa Inspectorial Salesiana de Alameda 2303 (esquina de R. Cumming). Luego, a fines de 1926, se trasladó a la comuna de Nuñoa, Chile-España 85. Pronto, adyacente a esta última dirección, se extendería a otras propiedades ( $\mathrm{N}^{\circ} 17$ y $\left.\mathrm{N}^{\circ} 101\right)$, aspecto que nos habla del rápido desarrollo de la obra.

A comienzos de 1928, su promotor nos refiere que en el $\mathrm{N}^{\circ} 85$, en cumplimiento de su programa, el proyecto ya dispone de oficinas, librería, y espacios para imprenta, encuadernación y bodega ${ }^{28}$. Igualmente, indica que desde el año anterior, en el lugar ha comenzado a funcionar una Escuela Tipográfica para niños y jóvenes, con alumnos internos, externos y medio-pupilos. Anuncia también que se ha puesto en marcha similar alternativa de formación para "damas, niñas y doncellas", a fin de que se habiliten en funciones comerciales y de difusión ${ }^{29}$. Para esto, ha contado con el respaldo del Arzobispo Crescente Errázuriz, quien dio orientaciones a los institutos y fieles de la Arquidiócesis para que acudieran con su generosidad a la reunión de los recursos necesarios.

La finalidad de la Escuela para hombres, era enseñar el arte de la tipografía en sus diversos ramos de encuadernación, cajas ${ }^{30}$, prensa y linotipia ${ }^{31}$. Con cupos limitados, se daría preferencia de matrícula "a aquellos que tengan disposición para ingresar

\footnotetext{
${ }^{26}$ En 1925, la librería del AP funcionó en la esquina de Bulnes con Romero. Estos espacios de venta no desaparecieron una vez hecho el cambio del AP a Ñuñoa.

${ }^{27}$ Véase nómina de títulos al final.

28 "Boletín del Apostolado de la Prensa", Año V, II, marzo 1928, pp.3-7 "Se ha escogido esta ubicación -nos expone el redactor de este Boletín- por sus especiales condiciones de salubridad, por la facilidad de locomoción (en poco más de un cuarto de hora se puede llegar al centro de la ciudad por los diversos tranvías y autobuses que recorren sus principales arterias), y para alejar de los peligros y de las distracciones de la gran urbe a los jóvenes que han de formarse en esta Escuela", Ibíd., p. 7.

${ }^{29}$ La sección femenina se situó originalmente en Irarrázaval 2260. Al año siguiente funcionará en Chile-España 101. Entre los cursos que se les impartirían, estaban dactilografía, encuadernación, costura y economía doméstica.

${ }^{30}$ Método de composición de tipos ordenados y ajustados a la caja de impresión.

${ }^{31}$ Máquina impresora a base de matrices variadas (tela, láminas de madera, metal).
} 
más tarde al Curso Superior del Apostolado de la Prensa, como linógrafos ${ }^{32}$, monotipistas $^{33}$, correctores de pruebas, redactores, gerentes de imprentas y librerías". A la vez que técnica, la formación se debía hacer en lo espiritual, moral e intelectual (cursos de literatura, filosofía, ciencias sagradas). Luego de un período de 5 años de aprendizaje, el egresado obtendría su Diploma de competencia ${ }^{34}$.

Cabe preguntarse por la cantidad de alumnos y alumnas que pasaron por estas escuelas, sus edades, procedencias y resultados efectivos, sin embargo, las informaciones del Boletín no nos proporcionan datos extendidos a este respecto. Una indicación de 1933, nos dice que entre los hombres -reunidos ahora en la Escuela y Externado Camilo Henríquez- se han formado 5 cursos de enseñanza preparatoria y uno como primer año de humanidades. No se proporciona igual información para las mujeres, nucleadas en la Escuela Nuestra Señora de la Sabiduría. En su conjunto, el comentario alude a la presencia de "aproximadamente 100 personas entre gente mayor y alumnado, alcanzando a cuarenta los internos" ${ }^{\prime 35}$.

En 1929 se agregarán antecedentes que muy posiblemente expliquen la salida de Gentilini de la Congregación Salesiana, en 1932: su interés por "despertar vocaciones sacerdotales" entre los jóvenes de la Escuela Tipográfica, así como los inicios, en octubre del año anterior, de los trabajos de construcción (en estilo gótico inglés) de la capilla del AP.

Con relación a lo primero, se agregarían algunos ramos de latín para los "más aprovechados", además de solicitar a los asociados nuevas contribuciones para sostener becas; en tanto que para cubrir en parte los gastos de la capilla, se encargaba a los cooperadores la venta de una rifa ${ }^{36}$, y que tanto ellos, sus familiares y amigos, hicieran sus compras de artículos religiosos y de escritorio, en un nuevo Bazar que se había abierto en el Apostolado. Los servicios de la capilla se destinarían especialmente a los colaboradores y familiares, sin dejar de lado las necesidades espirituales de la creciente población del barrio. Luego de su bendición, se esperaba que el templo entrara en funciones entre mayo y junio de 1929, como efectivamente ocurrió.

Sin cejar en su propósito de erigir un "Pío Instituto" formador de sacerdotes y religiosas de la buena prensa ${ }^{37}$, durante la primera mitad de los años 30, Gentilini dará a conocer los pasos de sus propósitos, apelando insistentemente a su grey a la entrega de nuevos y generosos esfuerzos pecuniarios.

\footnotetext{
${ }^{32}$ La linografía es la técnica de grabado sobre telas o géneros.

${ }^{33}$ Trabajo a base de la fundición individual de moldes o tipos.

${ }^{34}$ Las condiciones de acceso, se acuerdo a lo publicitado en 1928, estipulaban requisitos varios para los postulantes: fe de bautismo, certificado de buena conducta dado por un párroco o persona honorable; pagos de matrícula y pensión de acuerdo al régimen del alumno; ajuar, ropa marcada, catre, ropa de cama, guardapolvos y delantales, exigencias especialmente obligatorias para los internos. Finalmente, en el caso de internos, estos tendrían un sistema de visitas de padres y apoderados sólo los domingos, sin otro tipo de contactos a no ser que el Director del establecimiento lo permitiera. Cinco años más tarde (1933), aparecen las condiciones de que los futuros alumnos fuesen "hijos legítimos", debían disponer de certificado de confirmación y su edad no debía ser inferior a los 12 años. Con esto último, creemos, que se buscaba evitar el ingreso de niños pequeños sin instrucción preparatoria, afianzar la formación técnica, y favorecer la selección de potenciales nuevos religiosos. "Boletín del Apostolado de la Prensa", septiembre 1933, año IX, N²0, p.6. 35 Ibíd., p.2

${ }^{36}$ La rifa consideraba "valiosos objetos" como premios: diversos tipos de joyas, relojes, pinturas, vestidos de calidad, etc., entregados en donación. "Boletín del Apostolado de Prensa", abril 1929, año VI, N¹4, pp. 1 - 5.

${ }^{37}$ En palabras de Gentilini, Misioneras y Sacerdotes Apóstoles de la Prensa, debían ser formados en su centro.
} 
En lo inmediato, convierte la capilla del Apostolado en centro de devoción del Sagrado Rostro o Santa Faz, archicofradía internacional de origen francés. Retratos del rostro de Cristo y del fundador de la asociación gala, M. Dupont, "El santo hombre de Tours" (1851), ilustran varios de los Boletines. Al espacio comenzarán a llegar diversas personas y mensajes postales que ofrecerán obligaciones y brindarán gracias por favores concedidos, contribuyendo de alguna manera a la obra y a la fama del lugar.

En marzo de 1935 ya tenemos publicadas en el Boletín las "Condiciones" para el ingreso a la fraternidad, como también, el listado de "Promesas" divinas -de salvación y regocijo- que recaerían en todos los que se consagraran a la Sagrada Faz ${ }^{38}$. Junto con volverse un destino de peregrinación, devoción y ofrendas, se buscaba que cófrades, "niñas misioneras", celadores (as) estudiantes y legos "misionarán", esparciendo en distintos puntos de Santiago la obra de salvación del Apostolado, además de tener a su cargo la realización de la "colecta anual" en beneficio de los buenos libros.

Previo a esto, una breve nota del Boletín de noviembre de 1932, nos pone al tanto de un nuevo viaje del Director diocesano a Europa, específicamente a Italia, donde se entrevistó con el Papa Pío XI y las máximas autoridades salesianas de Turín. En el opúsculo donde relata aspectos de este desplazamiento -un viaje de "peregrinación", según sus dichos-, "apremiado por los intereses superiores del $\mathrm{AP}^{\prime \prime 39}$.

De vuelta en Ñuñoa, en mayo del mismo año redacta una carta al Rector Mayor de la Congregación, P. Pedro Ricaldone, donde le pide que la Pía Sociedad de Don Bosco emita una declaración formal en el sentido de que la Congregación "no reconoce ningún derecho en las propiedades que forman hoy la obra e Institución del "Apostolado de la Prensa"". Por este gesto, le promete que sabrá agradecer "y oportunamente, corresponder". Por de pronto, le comunica que su testamento ya lo ha hecho a favor de la Congregación ${ }^{40}$.

La nota a Ricaldone le había sido recomendada a Gentilini por el Arzobispo de Santiago. Hablando con él "en días pasados", Errázuriz le había hecho ver la conveniencia de que la Congregación expidiera tal declaración como forma "de evitar más tarde conflictos con los que nos sucedan, no conocedores de las cosas, no de cómo surgió la obra del Apostolado".

Se resolvía así una relación entre la Congregación y uno de sus miembros, relación que, paulatinamente, se había hecho insostenible para ambas partes.

\footnotetext{
38 "Boletín del Apostolado de la Prensa", Santiago, marzo de 1934, año XI, № 22, pp.17 - 21 . Este tipo de asociaciones tuvieron enorme vigor en la Francia postrevolucionaria. En particular, esta archicofradía tenía por fin promover diversas acciones que compartieran con Jesús el sacrificio a que había concurrido para la redención del hombre. Era un modo de solidarizarse con él, aplacando las iras de Dios por las innumerables ofensas a su dignidad que han cometido sus criaturas humanas.

${ }^{39}$ Op. cit. p.4.

${ }^{40}$ B. Gentilini, carta a Rdo. P. Ricaldone, Santiago 10 de mayo de 1932 (manuscrito). Indudablemente, el tenor prescriptivo de la carta, da cuenta del ánimo triunfal de Gentilini y una manera de ajustar cuentas con una jerarquía que, pocos años antes, lo había hecho morder la derrota. En Diario de una peregrinación, retrata elocuentemente su complacencia. De la cita con el Papa, nos señala: "Le esbocé el Programa que proponía desarrollar el Instituto del AP; lo aprobó y alentó y tuvo palabras de predilección para con los que trabajan y cooperan en él (...) Roma locuta est, causa finita est, pudimos decir con íntimo gozo del alma (...) Habíamos llegado a puerto después de tanta borrasca", Op. cit., p. 70.
} 
Eran diversas las circunstancias que no hacían aceptable para los superiores de la Congregación, la permanencia del sacerdote. Desde luego, su baja inserción en las actuaciones pastorales, especialmente educacionales, sello misional identitario de los seguidores de Don Bosco. Aparte de sus labores directivas cumplidas en Santiago y Concepción en la primera década del siglo, no se conocen de él quehaceres similares en años posteriores. Su entrega a los avatares editoriales, lo llevaron a evitar este tipo de funciones, seguramente poco estimulantes y de baja satisfacción respecto de intereses y anhelos protagónicos.

En el mismo orden de cosas, le habría resultado frustrante una vida religiosa rutinaria y que lo condenaba a estar probablemente alejado de las posibilidades de contacto con ambientes cultural y socialmente más ricos. Recordemos que él llega a Chile con $20 \mathrm{o}$ 21 años de edad, es decir, luego de haber vivido y conocido algún mínimo decisivo de la cultura italiana y europea ¿Por qué arriba a Chile, y lo hace por medio de los salesianos? Son cuestiones que escapan por ahora a nuestro manejo. Lo cierto es que, sea por sus muchas lecturas, su temprana y fecunda labor escritural, la necesidad de seguir conservando los idiomas italiano y francés, su rápida incursión en la lengua inglesa, o el creciente desarrollo de vínculos con el exterior, etc., su persona se nos muestra más como un misionero cosmopolita, que como un clérigo ajustado y obediente a las instrucciones jerárquicas.

De sus iniciativas editoriales y afanes por llegar a conformar una nueva congregación religiosa -elementos que de por sí provocarían el incomodo de la Casa Inspectorialemanan otros factores no menos desconcertantes para los jefes congregacionales: su ambición, su personalismo, su olfato para tocar las puertas adecuadas, sus tendencias al exhibicionismo intelectual y retórico. Su personalidad debió haber sido atractiva, más cuando por sus viajes e intercambios epistolares, podía dar cuenta de sus contactos directos con realidades y personeros -jincluyendo Papas!- admirados por nuestra clerecía y laicado. La separación de objetivos y estilos, ciertamente reconocidos por ambos lados, sembraba la discrepancia. Es sintomático, por lo demás, que en la capilla del Apostolado se entronizara una devoción mística (la Santa Faz) y no así una de estirpe Mariana, más adecuada a la salesianidad. Si hasta el propio Don Bosco o San Francisco de Sales, no ocuparon nunca, en sus gestiones y escritos, un lugar destacado, asunto inadmisible para un convencido salesiano.

Que la situación requería aclararse y resolverse entre la Congregación y su dependiente, quedó de manifiesto en el verano de 1925. El Consejo Inspectorial, tras varias deliberaciones que incluyeron incluso a la jerarquía turinesa, somete al Apostolado de la Prensa a estrictas determinaciones, que Gentilini acatará sólo temporalmente.

En nota dirigida al regente del Apostolado, le señala que, en adelante, corresponderá al Inspector de la Congregación en Chile, la tutela completa sobre la obra editorial. En tal sentido, esta autoridad debía conocer del movimiento general de sus actividades, así como entregar su visto bueno a todo lo que fuera a entrar en prensa. De igual modo, cada seis meses, haría reconocimiento de inventarios de bienes muebles e 
inmuebles, además de visar los balances financieros. El único dueño de la obra de difusión sería la Congregación, sanción que debía incorporarse en sus reglamentos o estatutos del Apostolado, y ninguna modificación a los mismos podía hacerse sin el consentimiento de la jefatura inspectorial. En cuanto a los colaboradores y socios del Apostolado, debían aceptar ser considerados en lo sucesivo como "verdaderos cooperadores salesianos", reconociendo como autoridad sólo a los superiores de la Congregación. El "Director de la Casa" (Gentilini), mantendría facultades y atribuciones acotadas únicamente a la obra, pero siempre y cuando esa autoridad no contraviniera lo dispuesto por la Congregación ${ }^{41}$.

La aceptación de Gentilini de estas normas fue un asunto pasajero. Descontento con lo resuelto, tomará contacto directamente con Turín de donde, finalmente, conseguirá se acceda a su propuesta de hacer del Apostolado una obra independiente, manteniendo vínculos puramente filiales con la Congregación, figura que le aseguraba su rango sacerdotal $^{42}$. Estas gestiones turinesas seguramente agravaron irreversiblemente los hechos. Se podría incluso decir que en esto fue desafiante y contumaz, una suerte de ofensa para sus superiores en Chile.

Si bien nunca las relaciones entre el salesiano y su Congregación fueron óptimas ${ }^{43}$, es posible reconocer que la misma, de algún modo, lo dejó hacer. Tal vez si por las influencias y amistades del presbítero, su talante intelectual o por sus vínculos con el exterior -sin descontar el hecho de que era un italiano en una organización donde primaba tal nacionalidad-, no es dable suponer la carencia completa de voluntad ${ }^{44}$. Como ya vimos, el qué del asunto no radicó en su contenido: la siempre sensible área comunicacional, sino en el cómo: la gestión editorial debía darse como obra institucional salesiana. Pero cuando a Gentilini el ambiente salesiano se le presentó complicado, y a las dificultades habituales se sumaron las sospechas sobre sus modos de actuación, no tuvo mayores aprensiones para buscar un nuevo marco de acción. Es ese el instante en que rechaza la opción que le ofrece la Congregación (1925), favoreciendo la independización del AP (y de él mismo).

Desligado de la Congregación, tendría campo abierto para emprender las iniciativas organizacionales que describimos en las páginas precedentes. Su frágil filiación salesiana cursará el camino del alejamiento definitivo de las filas de Don Bosco. En sus años finales (1932-1936), profesará en el clero secular capitalino. Por indicación testamentaria, sus restos yacen aún en la bóveda mortuoria de la Pía Sociedad Salesiana del Cementerio Católico de Santiago.

\footnotetext{
${ }^{41}$ Carta del Visitador Extraordinario Rdmo. Pbro. José Vespignani a Bernardo Gentilini, Santiago, 24 de marzo de 1925. Archivo Congregación Salesiana.

${ }^{42}$ Carta de Bernardo Gentilini al Inspector Congregación Salesiana en Chile, Santiago, 10 de julio de 1926. Archivo Congregación Salesiana.

${ }^{43}$ En diferentes fechas, Gentilini deja entrever las dificultades y poca comprensión que habían afectado a sus planes y trabajos en el Apostolado de la Prensa. No especifica la causa de estos problemas, sin embargo, sus insinuaciones nos mueven a referirlos a la Congregación.

${ }^{44}$ Es importante anotar que el cosmopolitismo de Gentilini y contar con importantes vínculos con Europa, se debía, de modo específico, a la destacada presencia de su familia boloñesa en las altas esferas de la política romana en un momento de auge en Italia del movimiento fascista. De hecho, un sobrino de él, Dino Grandi, fue un prominente colaborador de Mussolini, siendo Ministro de Relaciones Exteriores del Duce, entre 1929 y 1932.
} 


\section{Palabras finales}

Bernardo Gentilini dispuso para sí convertirse en un actor destacado del ideal de la Buena Prensa, es decir, de aquel horizonte nocional que tan fuertemente marcara la concepción comunicacional de masas de la Iglesia Católica mundial en el período que fue del último cuarto del siglo XIX, hasta las primeras décadas del XX. En él se perfilaron cualidades de gestión muy próximas a lo que hoy -luego de décadas de ideología neoliberal- conceptualizamos como "sujeto emprendedor", es decir, un tipo de conducta industriosa que es capaz de proponer ideas, articular proyectos y movilizar recursos en vistas a determinados fines productivos. En esta perspectiva, por sobre su doctrinarismo religioso tradicionalista, fue un personaje moderno al modo renacentista, un apóstol dispuesto a vencer frente a todo y sostenido en la sola convicción ético-mística que le proveía su fe absoluta en la Providencia.

De su amplia producción literaria, poco o nada le sobrevivió, olvidándose en desconocidos anaqueles de bibliotecas inconsultas, corolario que, sin embargo, ya en sus últimos años de vida venía anunciándose.

Para mediados de los años 30, el concepto de la Buena Prensa de orden eminentemente devocional practicado por Gentilini y otros, resultaba imposible ante las mudanzas modernizadoras de la sociedad. Había tenido el mérito de llevar a la Iglesia a atreverse en un ámbito que temía y desconocía: el dela exposición pública, a través de la prensa, de visiones e intereses, debiendo, en consecuencia, asumir las ventajas y desventajas que el paso implicaba. Y hacerlo, como siempre ocurre, con lo que se tenía, para percatarse luego de lo que no se tenía, volviendo limitada la experiencia. Evidenciándose que la forma resultaba ineficaz y nuevas alternativas comunicacionales (radio, cine) la amenazaban con más rezago, había llegado el momento de explorar otras opciones para la Buena Prensa católica. 


\section{Obras de Bernardo Gentilini según año de publicación}

\begin{tabular}{|c|c|}
\hline Obras de Bernardo Gentilini & Año de publicación \\
\hline Total 234 & \\
\hline Spiga d'Oro, 10 volúmenes pequeños, en italiano & 1902-1904 \\
\hline Epis Glanés, varias ediciones, francés & 1904-1905 \\
\hline Giornata d'amore nei S. Cuore, italiano & 1902 \\
\hline Rays of light, 6 opúsculos, en inglés & 1902 \\
\hline Manual polígloto & 1903 \\
\hline Diario del Alma, 6 volúmenes & 1904 \\
\hline Chistes y verdades & 1905 \\
\hline Haces de Luz & 1910 \\
\hline El apostolado de la prensa. La misión de los buenos libros & 1911 \\
\hline El libro del Superior o Superiora & 1913 \\
\hline Leyendas y cuentos alegres & 1913 \\
\hline El manual del educador, 2 tomos & 1914 \\
\hline Hora Santa & 1914 \\
\hline La catequesis & 1914 \\
\hline El Clergyman norteamericano & 1915 \\
\hline La ciencia del bien morir. En el ocaso de la vida & 1915 \\
\hline Meditaciones & 1915 \\
\hline Meditaciones para el mes & 1915 \\
\hline Charlas sobre modas y otros tópicos del mundo femenino & 1916 \\
\hline El libro de la joven, o sea, preparación moral de la joven para la vida & 1916 \\
\hline El libro del escolar & 1916 \\
\hline El orador sagrado & 1916 \\
\hline Estudio psicológico sobre el sectarismo & 1916 \\
\hline Ilustres convertidos & 1916 \\
\hline La fe y la ciencia & 1916 \\
\hline La Masonería y las sociedades secretas & 1916 \\
\hline Catecismo en ejemplos & 1917 \\
\hline El arte de la alegría y el arte de la felicidad & 1917 \\
\hline El libro de la mujer. Como cristiana, esposa, madre, educadora y apóstol & 1917 \\
\hline El libro del Apóstol social & 1917 \\
\hline El libro del sacerdote & 1917 \\
\hline Higiene moral, o sea, la higiene del alma y la higiene de las pasiones & 1917 \\
\hline Las grandes víctimas de la ignorancia, de la duda & 1917 \\
\hline
\end{tabular}




\begin{tabular}{|c|c|}
\hline Manual de sabiduría y filigrana religioso-literaria & 1917 \\
\hline Castigo a los blasfemos y otros profanadores & 1918 \\
\hline El libro del Apóstol de la Prensa & 1918 \\
\hline El libro del hombre varonil. Como cristiano y caballero, esposo, padre y educador... & 1918 \\
\hline El libro del niño. & 1918 \\
\hline Humoradas & 1918 \\
\hline La Biblia y la Ciencia & 1918 \\
\hline Objeciones modernas contra la fe & 1918 \\
\hline Conferencias morales. Sobre la Providencia & 1919 \\
\hline Doctrinas sociales & 1919 \\
\hline Educación moral del corazón & 1919 \\
\hline El arte de la propia ilustración y la higiene intelectual & 1919 \\
\hline El Catolicismo y el Pontificado a través de los siglos & 1919 \\
\hline El libro del enfermo y el atribulado & 1919 \\
\hline La ciencia y el arte de la salud por medio de la medicina natural (Fisioterapia) & 1919 \\
\hline La democracia cristiana & 1919 \\
\hline La educación del corazón & 1919 \\
\hline La instrucción laica & 1919 \\
\hline La restauración social y religiosa & 1919 \\
\hline Nuevas orientaciones sociales & 1919 \\
\hline El alcoholismo & 1920 \\
\hline El socialismo y el maximalismo & 1920 \\
\hline Filigrana religioso-literaria & 1920 \\
\hline La educación del niño, o sea, Paidología & 1920 \\
\hline Secretos y consejos para felicidad y la santificación de la vida & 1920 \\
\hline ¿Es la religión la fuerza social más poderosa del mundo? & 1921 \\
\hline Dante Alihgieri & 1921 \\
\hline De la educación y del sistema preventivo & 1921 \\
\hline El concepto de la propiedad y los deberes de la riqueza & 1921 \\
\hline El libro del joven, o sea, preparación moral del joven para la vida & 1921 \\
\hline La Espiga, 9 volúmenes & 1921 \\
\hline La lumbrera del mundo. La Iglesia en la Edad Media & 1921 \\
\hline Orientación pastoral y organización parroquial & 1921 \\
\hline $\begin{array}{l}\text { Al margen del gran fracaso socialista y comunista } \\
\text { Algo sobre indumentaria femenina y otros tópicos curiosos. Una cruzada } \\
\text { de modestia cristiana }\end{array}$ & 1922 \\
\hline Bocetos edificantes y charlas amenas & 1922 \\
\hline
\end{tabular}




\begin{tabular}{|c|c|}
\hline Cartas a los eclesiásticos de América & 1922 \\
\hline De la oración & 1922 \\
\hline El ateísmo y los ateos & 1922 \\
\hline El cine ante la pedagogía y la medicina, ante la moral y la religión & 1922 \\
\hline El Diario de un filósofo & 1922 \\
\hline El libro del anciano & 1922 \\
\hline El Pan Eucarístico & 1922 \\
\hline La incredulidad y los incrédulos & 1922 \\
\hline La instrucción moral & 1922 \\
\hline La sinrazón del protestantismo & 1922 \\
\hline Santoral. Vida de los santos & 1922 \\
\hline "Ser o no ser" & 1923 \\
\hline ¡Leed la Biblia! & 1923 \\
\hline ¿Separación o persecución? Las grandes lecciones de la historia & 1923 \\
\hline Chistes y Verdades. Nueva serie & 1923 \\
\hline Diario de viaje & 1923 \\
\hline El llamamiento divino al apostolado sacerdotal & 1923 \\
\hline El Sermón de la Montaña & 1923 \\
\hline Episodios edificantes de la Gran Guerra & 1923 \\
\hline Florilegio psicológico literario & 1923 \\
\hline Hacia Roma. Ilustres protestantes convertidos & 1923 \\
\hline Jesucristo. Su divinidad, su Iglesia, su reinado social & 1923 \\
\hline La religión y los sabios & 1923 \\
\hline La teoría y la práctica de la Santidad & 1923 \\
\hline La Virgen María & 1923 \\
\hline Novísima serie de chistes y verdades & 1923 \\
\hline Purgatorio. La expiación de ultratumba & 1923 \\
\hline El Anticristo & 1924 \\
\hline El divorcio & 1924 \\
\hline El Espiritismo & 1924 \\
\hline El ocaso de un ídolo. Renan y su obra & 1924 \\
\hline Ensayo sobre indiferentismo & 1924 \\
\hline La moral laica & 1924 \\
\hline La prensa católica & 1924 \\
\hline Las Órdenes religiosas & 1924 \\
\hline Manual de Apologética, o sea, Fundamentos de la Fe & 1924 \\
\hline
\end{tabular}




\begin{tabular}{|c|c|}
\hline Manual de doctrina cristiana, 2 tomos & 1924 \\
\hline Risas y lágrimas & 1924 \\
\hline Alborada de la Fe. Cartas a Teófilo & 1925 \\
\hline Daniel & 1925 \\
\hline El baile & 1925 \\
\hline El bandolerismo del siglo XX & 1925 \\
\hline El católico en la acción social & 1925 \\
\hline El católico en la vida pública & 1925 \\
\hline El Universo. Conferencias científico-morales & 1925 \\
\hline Isaías, si el Profeta resucitara & 1925 \\
\hline Job. El poema del dolor humano & 1925 \\
\hline Páginas americanas resonancias de viaje (EE.UU.) & 1925 \\
\hline Saetas de amor divino & 1925 \\
\hline Tolerancia e intolerancia & 1925 \\
\hline Una conspiración mundial judío-masónica & 1925 \\
\hline De la mística & 1926 \\
\hline El Eclesiastés & 1926 \\
\hline El Espíritu Santo & 1926 \\
\hline El Sagrado Corazón de Jesús & 1926 \\
\hline Homilías sobre los Evangelios de los domingos & 1926 \\
\hline Ilustres hombres de armas (militares) & 1926 \\
\hline La libertad de enseñanza & 1926 \\
\hline La modestia cristiana & 1926 \\
\hline Los nuevos convertidos. Escritores y poetas & 1926 \\
\hline Sanitas. Purificación por la hidroterapia & 1926 \\
\hline Verdades de todos los colores & 1926 \\
\hline Buzón de Cuestiones. Acerca del Protestantismo y otras sectas & 1927 \\
\hline ElEclesiástico & 1927 \\
\hline El Libro de la Sabiduría & 1927 \\
\hline El Sermón de la Cena & 1927 \\
\hline Ilustres creyentes & 1927 \\
\hline La gran civilizadora del Mundo & 1927 \\
\hline La Providencia. Consideraciones & 1927 \\
\hline La vocación de las doncellas & 1927 \\
\hline Los conflictos entre la fe y la ignorancia & 1927 \\
\hline Manual de historia eclesiástica & 1927 \\
\hline
\end{tabular}




\begin{tabular}{|c|c|}
\hline Tipos en solfa & 1927 \\
\hline ¡Plus Ultra! & 1928 \\
\hline El huésped eucarístico & 1928 \\
\hline Ilustres estadistas creyentes & 1928 \\
\hline La hora de Satanás & 1928 \\
\hline La medianera universal. La Virgen María & 1928 \\
\hline La muerte a la luz de la fe y de la ciencia & 1928 \\
\hline Los mártires de México, 2 tomos & 1928 \\
\hline Manual de la primera comunión y la confirmación & 1928 \\
\hline Mies Evangélica & 1928 \\
\hline San Juan & 1928 \\
\hline San Pablo, 2 tomos & 1928 \\
\hline San Pedro & 1928 \\
\hline Tobías. Dedicado a las familias cristianas & 1928 \\
\hline Verdades Eternas & 1928 \\
\hline $\begin{array}{l}\text { Acerca del feminismo } \\
\text { Curso de energética dedicado especialmente a los jóvenes. Educación de la } \\
\text { voluntad, formación del carácter, gobierno de la vida }\end{array}$ & 1929 \\
\hline El comunismo juzgado por sus frutos & 1929 \\
\hline El libro de los aforismos & 1929 \\
\hline El libro del propagandista católico & 1929 \\
\hline El Salterio de David & 1929 \\
\hline El teosofismo & 1929 \\
\hline La indumentaria femenina & 1929 \\
\hline La limosna & 1929 \\
\hline ¿Se acerca el reinado del anticristo? & 1930 \\
\hline El arte de saber comer & 1930 \\
\hline El gran medio de salvación. La Contrición perfecta & 1930 \\
\hline El sigilo sacramental & 1930 \\
\hline Homilías sobre las Epístolas de los domingos & 1930 \\
\hline La Epístola de Santiago Apóstol & 1930 \\
\hline La pasión de N. S. J.C. & 1930 \\
\hline La vocación religiosa & 1930 \\
\hline La vocación sacerdotal. El llamamiento divino & 1930 \\
\hline Lo que hay sobre el Infierno & 1930 \\
\hline Los Evangelios y los Hechos de los Apóstoles & 1930 \\
\hline San Judas & \\
\hline
\end{tabular}




\begin{tabular}{|c|c|}
\hline Santificar las fiestas & 1930 \\
\hline Tesoros espirituales & 1930 \\
\hline Trapos al sol & 1930 \\
\hline Buzón de preguntas & 1931 \\
\hline De la Gracia & 1931 \\
\hline El acto de amor perfecto & 1931 \\
\hline El libro de las Consultas & 1931 \\
\hline El mentalismo & 1931 \\
\hline Filosofando desde el mirador de un filósofo & 1931 \\
\hline La caridad fraternal. Conferencias & 1931 \\
\hline Los Proverbios de Salomón & 1931 \\
\hline Otros Convertidos & 1931 \\
\hline Profecías. Acerca de los últimos tiempos & 1931 \\
\hline Un pensamiento al día & 1931 \\
\hline ¡Venga a nos el tu Reino! & 1932 \\
\hline Algunos famosos masones convertidos & 1932 \\
\hline Diario de una peregrinación & 1932 \\
\hline El Teatro & 1932 \\
\hline Ilustres protestantes convertidos & 1932 \\
\hline Los Místicos españoles & 1932 \\
\hline Los siete dones del Espíritu Santo & 1932 \\
\hline Manual de piedad & 1932 \\
\hline San José. Su vida y sus glorias & 1932 \\
\hline Tratado de pedagogía moral y cristiana & 1932 \\
\hline Biografías de niños célebres & 1933 \\
\hline Cartas a los jóvenes & 1933 \\
\hline De las pasiones, en general y de la ira y otras pasiones en particular & 1933 \\
\hline El Ángel de la Guarda & 1933 \\
\hline El Salterio de la Confianza & 1933 \\
\hline En la escuela de la experiencia & 1933 \\
\hline Estética espiritual & 1933 \\
\hline Estética, conferencias & 1933 \\
\hline La respuesta de Dios a los blasfemos y profanadores & 1933 \\
\hline La respuesta de Dios a los perseguidores de la Iglesia y sus ministros & 1933 \\
\hline Los horrores de Rusia & 1933 \\
\hline Un nuevo Evangelio de Paz. Predicado en 1925, Novela 2da Ed. & 1933 \\
\hline
\end{tabular}




\begin{tabular}{|l|r|}
\hline El Diablo a la luz de la fe, de la razón y de la tradición & 1934 \\
\hline El libro de la Niña & 1934 \\
\hline El libro del aprendiz & 1934 \\
\hline Historia de vocaciones célebres & 1934 \\
\hline La presencia de Dios & 1934 \\
\hline Por la moral en la literatura y arte. Las más palpitantes cuestiones de hoy día & 1934 \\
\hline Por la moral social & 1934 \\
\hline Porro Unum. La salvación del alma & 1934 \\
\hline Un arma de combate: la prensa. Los adalides de la pluma & 1934 \\
\hline Educación de la castidad & 1935 \\
\hline El apostolado del sufrimiento & 1935 \\
\hline El Cantar de los Cantares & 1935 \\
\hline El libro de los esposos. Novios y nóveles esposos & 1935 \\
\hline El libro doméstico y del obrero (o artesano) & 1935 \\
\hline El Padrenuestro & 1935 \\
\hline El sacerdote en la misa y en oficio divino & 1935 \\
\hline Homilías sobre la liturgia de los domingos & 1935 \\
\hline La psicología de los Santos & 1935 \\
\hline La Santa Misa & 1935 \\
\hline Miel sobre hojuelas & 1935 \\
\hline Ensayo sobre la libertad & 1936 \\
\hline
\end{tabular}

